\title{
The Flipped Classroom: Viewpoints in Asian Universities
}

\author{
Chua Shu Min Joanne ${ }^{1}$, Fatimah Lateef ${ }^{2,3}$ \\ ${ }_{1}^{1} 3^{\text {rd }}$ Year Medical Student, Royal College of Surgeons in Ireland (RCSI), Ireland. ${ }^{2}$ Senior Consultant, Director \\ of Undergraduate Training and Education, Director of The Institute of Medical Simulation and Education, \\ Singapore General Hospital. ${ }^{3}$ NUS Graduate Medical School and Yong Loo Lin School of Medicine, National \\ University of Singapore.
}

\section{ARTICLE INFO}

Received : :24/09/2014

Accepted : : 20/10/2014

Published : :01/12/2014

\section{KEYWORD}

Flipped classroom

Asia

Pedagogy

Learning culture

\section{ABSTRACT}

Introduction: The flipped classroom is a radical pedagogy whereby online lectures take place outside class, and the conventional classroom is used for active problem solving. It has successfully met the approval of students and teachers alike in the Western world. Objective: This paper aims to evaluate the response to flipped classroom teaching in Asian schools. Asian students stereotypically learn differently from their Western counterparts hence their receptivity to flipped classrooms may also vary. Method and Result: Collective results from twelve case studies carried out in Asia reflect a positive response from majority of the Asian students who experienced the flipped classroom. Conclusion: The flipped classroom, although a relatively new model of practice in Asia, appears to be gaining momentum and is well-received. These findings not only fuel the necessity for more resources to be channelled into furthering the potential of the flipped classroom in Asia, they can also be of special value to schools with a strong international culture worldwide.

(c) Medical Education Department, School of Medical Sciences, Universiti Sains Malaysia. All rights reserved.

CORRESPONDING AUTHOR: Assoc Prof Fatimah Lateef, Dept of Emergency Medicine, Singapore general Hospital, Outram Road, Singapore 169608. Email: Fatimah.abd.lateef@sgh.com.sg

\section{An Overview of the Flipped Classroom}

The flipped classroom has long existed in various forms, but was popularized and solidified as a model by Jonathan Bergmann and Aaron Sams $(1,2)$. They first published a book on it in 2012, titled "Flip Your Classroom: Reach Every Student in Every Class Every Day"(1, 2). This model aims to reform age-old teaching methods that are inefficient and often fail to engage students in the classroom (3). The flipped classroom is a concept whereby schoolwork is done at home and homework is done at school (1).
Also known as the 'inverted classroom', the flipped classroom has infiltrated many classrooms in the West. Media like the The New York Times (4) and The Washington Post (5) have even reported on it. Books deliberating it have surfaced and teachers themselves have tried, tested and advocated it (2-10). Following the widespread success of the flipped classroom as reported in the West, this paper aims to discover the response of Asian users. To our knowledge, this is the first paper to report on the Asian perspective of the flipped classroom model. 


\section{Learning Styles}

Culture is central to influencing how a person thinks and behaves (7). Western and Eastern upbringing differ vastly in terms of philosophy, values and cultural backgrounds (6). Nisbett dates these distinctions back to primeval Greece and China (6). Wang, attributes the differences to Confucian philosophy and Judeo-Christian heritages influencing Easterners and Westerners respectively (7). As a result, stereotypes regarding how students in the East and West learn respectively have long existed (6-8).

Asian students are often thought of as passive learners whereas their Western counterparts are the opposite (11). Asian students preferred to learn as a group and extensively relied on the teacher as a leading source of information (7). This is contrasted with Western students who highly valued individualism and independent learning (7). The flipped classroom requires students to learn autonomously at home using online video lectures and actively participate in class for effective discussions. While these criteria seem to indulge Westerners, Asian students pre-accustomed to 'so-called' laid-back learning may, in specific context, feel some degree of disorientation (7).

Asian and Western students may also view the role of the teacher differently. To many in Asia, the teacher is often a 'sage on the stage'. In China, the teacher ranked among the top five persons who received utmost reverence by society, alongside parents and the emperor (12). This can translate into Asian students obeying teachers without independent thinking; reflected in the recent tragedy of a South Korean ferry shipwreck whereby students complied and stayed put despite the sinking vessel (13). In a flipped classroom model, teachers are no longer distant figures at the front of class. Rather, they are expected to work alongside students, guiding them individually. This may cause distress to students and teachers who have long maintained traditional hierarchical beliefs.

\section{Selection of Case Studies in Asia}

A search for case studies was carried out in August 2014 using PubMed and Google Scholar as databases. Our search strategy involved obtaining a list of all the countries in Eastern, Northern, South Central and South East Asia (14) and manually typing each country into the search bar followed by the keywords 'flipped classroom', 'inverted classroom' or 'flipped learning' respectively in each search. This is illustrated in Table 1.

Table 1: Search strategy used to collect case studies in Asia

\begin{tabular}{|c|c|c|}
\hline \multicolumn{2}{|c|}{ List of countries in Asia (14) } & $\begin{array}{l}\begin{array}{l}\text { Search } \\
\text { strategy for } \\
\text { each country }\end{array} \\
\text { Search 1: }\end{array}$ \\
\hline $\begin{array}{l}\text { Afghanistan } \\
\text { Bangladesh } \\
\text { Bhutan } \\
\text { Brunei } \\
\text { Cambodia } \\
\text { China } \\
\text { Hong Kong } \\
\text { India } \\
\text { Indonesia } \\
\text { Iran } \\
\text { Japan } \\
\text { Kazakhstan } \\
\text { Kyrgyzstan } \\
\text { Laos } \\
\text { Macau } \\
\text { Malaysia } \\
\text { Maldives } \\
\text { Mongolia } \\
\text { Myanmar }\end{array}$ & $\begin{array}{l}\text { Nepal } \\
\text { North Korea } \\
\text { Pakistan } \\
\text { Philippines } \\
\text { Russia } \\
\text { Singapore } \\
\text { South Korea } \\
\text { Sri Lanka } \\
\text { Taiwan } \\
\text { Tajikistan } \\
\text { Thailand } \\
\text { Tibet } \\
\text { Timor-Leste } \\
\text { Turkmenistan } \\
\text { Uzbekistan } \\
\text { Vietnam }\end{array}$ & 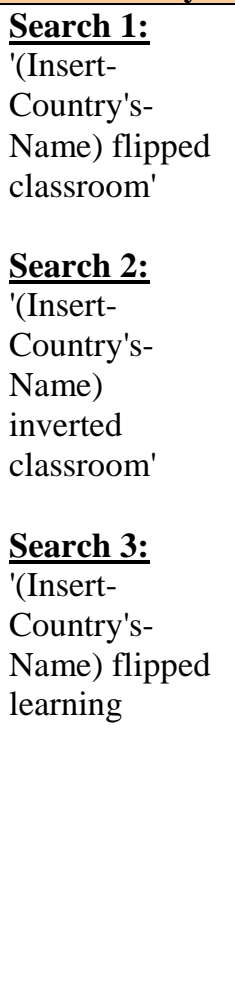 \\
\hline
\end{tabular}

Inclusion and exclusion criteria for the selection of case studies are detailed in Table 2. Case studies had to be conducted in Asian countries on university students, with locals forming more than half of the sample population. The studies had to have appropriately 'flipped' classrooms whereby students learnt material at home using online resources and spent classroom hours in active discussion, active problem solving or theory application, facilitated by a teacher. All 
case studies had to obtain participant feedback after the flipped class in the forms of surveys or focus groups. Articles not published in coherent English or written in another language were excluded. As a result, twelve case studies from Singapore (15-17), Malaysia (18), China (19),
India (20), Hong Kong (21), South Korea (22), Taiwan (23, 24), Russia (25) and Japan (26) fulfilled the criteria for this review. Table 3 categorizes the studies by country.

Table 2: Inclusion and exclusion criteria for the selection of case studies

\begin{tabular}{|c|c|c|c|}
\hline \multicolumn{2}{|c|}{ Inclusion Criteria } & \multicolumn{2}{|c|}{ Exclusion Criteria } \\
\hline 1. & Case studies conducted in Asian countries & 1. & Articles not published in coherent English \\
\hline 2. & University level students & 2. & $\begin{array}{l}\text { Case studies with less than half of the sample } \\
\text { population being locals of the Asian country }\end{array}$ \\
\hline 3. & One clear topic was selected to be flipped & & \\
\hline 4. & $\begin{array}{l}\text { Students were familiarized with the concept of a } \\
\text { flipped class before they participated in it }\end{array}$ & & \\
\hline 5. & $\begin{array}{l}\text { Online material covering theoretical aspects of the } \\
\text { course was available to students before class }\end{array}$ & & \\
\hline 6. & $\begin{array}{l}\text { Class time was used for open discussion, active } \\
\text { problem solving or applications of theory }\end{array}$ & & \\
\hline 7. & $\begin{array}{l}\text { Evaluation of student feedback was done after the } \\
\text { flipped class }\end{array}$ & & \\
\hline
\end{tabular}

Table 3: Selected case studies by country

\begin{tabular}{|c|c|c|c|c|c|c|c|c|}
\hline Singapore & Malaysia & China & India & $\begin{array}{l}\text { Hong } \\
\text { Kong }\end{array}$ & $\begin{array}{l}\text { South } \\
\text { Korea }\end{array}$ & Taiwan & Russia & Japan \\
\hline $\begin{array}{l}\text { Linga et al., } \\
2014\end{array}$ & $\begin{array}{l}\text { Jamaludin et } \\
\text { al., } 2014\end{array}$ & $\begin{array}{l}\text { Zhang, } \\
2014\end{array}$ & $\begin{array}{l}\text { Sureka, } \\
2013\end{array}$ & $\begin{array}{l}\text { Sharma, } \\
2013\end{array}$ & $\begin{array}{l}\text { Choi, } \\
2013\end{array}$ & Wan, 2012 & $\begin{array}{l}\text { Atabekova, } \\
2013\end{array}$ & $\begin{array}{l}\text { Ishikawa et } \\
\text { al., } 2014\end{array}$ \\
\hline Corrias, 2014 & & & & & & $\begin{array}{l}\text { Chen et al., } \\
2014\end{array}$ & & \\
\hline Ong, 2014 & & & & & & & & \\
\hline
\end{tabular}

Table 4: Key questions used to evaluate the case studies

\begin{tabular}{|l|l|}
\hline \multicolumn{2}{|l|}{ Key Questions (KQ) } \\
\hline 1. & Did the sample population approve of the flipped classroom? \\
\hline 2. & Are there objective indicators showing the benefit of the flipped classroom? i.e., improvement in grades \\
\hline 3. & Did the case study recommend that the flipped classroom model should be continued? \\
\hline
\end{tabular}

The twelve case studies differed in types of evaluative feedback obtained. For the purposes of this paper, we assessed each case study using three key questions (KQs) to determine their viewpoint of the flipped classroom. Table 4 details the three KQs. For the case studies that did not explicitly answer the KQs; their input was excluded when evaluating that particular key question.

\section{Evaluation of the case studies}

The case studies were obtained from 9 different countries in Asia and across a broad range of university disciplines including engineering, computing and medicine. Hence, feedback on the flipped classroom obtained in this study is largely reflective of the opinions of Asian university students and their teachers. The case studies also varied in sample population from 24 
to 344 participants, showing that flipped classroom can be applied to classes of most sizes.

Key question one (KQ1) showed that $100 \%$ of the case studies that answered the question reported that a majority of their sample population approved of the flipped classroom model. Linga et al., showed $90 \%$ of their qualitative comments were positive (15). Corrias, found that $50.5 \%$ of participants preferred video lectures to traditional lectures (16). Ong, noted over $90 \%$ of participants in their trial preferred the flipped classroom to traditional methods (17). Jamaludin et al. showed that a majority of participants answered positively to the statement: 'When I'm in this (flipped) class, I feel good'(18). Sureka, showed that $62.5 \%$ of participants benefitted from the extra time with their instructors in the flipped trial and would not have had such an opportunity otherwise (20). Sharma displayed that $75 \%$ of participants answered 'yes' to 'Would you like future class sessions to be delivered in this way? (21)' Choi, noted in his study with a control group that 'student satisfaction on feedback in inverted classroom is higher than that in traditional lecture group' (22). Wan also noted that 'more than $90 \%$ of students would like to recommend this course to others' (23). Chen et al. showed 94\% of their participants felt the flipped classroom model provided many advantages for learning (24). Atabekova, showed that participants agreed that the flipped classroom 'enhances ways of knowledge transmission, processing, acquisition and reconstruction' (25). Ishikawa et al. noted their participants even believed strongly, that they would likely perform better in exams (26).

From KQ1, a majority of Asian students embraced the flipped classroom model despite arguments that the flipped class may not work as well in Asia as it did with Western students.

Key question two (KQ2) sought to elicit objective indicators that could prove the flipped classroom was of benefit. Linga et al. compared the examination results of participants with nonflipped students from the previous three years (15). The trial students performed as well as their non-flipped counterparts, despite the official teaching hours being reduced (15). Choi, compared students who had undergone a flipped classroom with a control group and the results showed 'no significant differences in written exam grades, project evaluation score and lecture satisfaction' (22). Chen et al. also reported no significant difference in grade averages of trial participants with non-flipped counterparts from the previous two years (24).

From KQ2, no conclusions can be made on whether the flipped classroom can improve participants' grades, due to insufficient available data. Objective measures like the participants' grades are useful tools in gauging the level of learning achieved, hence future studies should obtain such data for more valid evaluation of the flipped classroom model.

Results from key question three (KQ3) showed that $100 \%$ of the studies recommended the flipped classroom model. Linga et al., showed participants strongly welcomed the unconventional model (15). Corrias, recommended 'it would be interesting to collect more data from future runs of this course' to validate their positive findings (16). Ong, praised the model in teaching challenging topics that had been called 'yawn-inducing' and 'difficult to learn' (17). Jamaludin et al. noted the model created a 'caring environment designed to enhance student engagement' (18). Zhang discovered that the flipped classroom helped slower students and listed many other benefits (19). Sureka, highlighted the positive survey feedback received (20) Sharma also listed the pros and cons of the model and recommended further trials (21). Choi, suggested improvements of their video material for future trials (22). Wan, cited a significant majority of their participants approving the flipped classroom (23). Chen et al. promoted the flipped classroom model and recommended their own 'FLIPPED' model (24). Atabekova, maintained the importance of shifting the focus towards active learning in the classroom (25) while Ishikawa concluded that their participants were happy with the flipped class (26). 
From KQ3, all case studies in this review approved of the flipped classroom concept, however many also cited challenges requiring special attention in order for the model to reach its full potential.

\section{Success of the flipped classroom model in Asia}

Previous evidence suggests differences in the attitudes of Asian and Western students in the classroom and how they view the teacher's role. These differences and perceptions casted doubt on feasibility of the flipped classroom in Asian classrooms. Twelve case studies were evaluated and all reported success in their respective schools.

Communities are no longer isolated because of globalization (27). Various mediums connect students with the world and a rising number of students have the opportunity to study abroad (28). Traditionally held cultural practices may slowly dilute with each generation, therefore making the differences between the east and west not veer so much to opposite ends of the scales, as before.

The current generation of students in Asia has broken out of the stereotypical learning mold. Millennial are born into a time where information is at their fingertips via the Internet and teachers cease to be their primary source of information. Increasingly, informed students may become dissatisfied with being 'taperecorders' in class and desire to take ownership of their own educational path. The flipped classroom allows advancement at their own pace and engagement with their teacher on a personal level to best supports their learning. More Asian students are also viewing the world as their oyster (29) and placing higher emphasis on developing skills to help them thrive in various parts of the world. Soft skills such as public speaking and critical thinking may become additionally appreciated by students; another reason why the flipped class concept can succeed in Asia.

Educators in Asia are also actively seeking to enhance student learning. The University of
Hong Kong has developed an application named 'iClass' in a bid to increase classroom interactivity (30). In Singapore, notable universities have teamed up allowing students to receive a unique brand of education with influences from the East and the West. Such schools include the DUKE-NUS Graduate Medical School (31) and the Singapore-MIT Alliance for Research and Technology (32). The flipped classroom can work in Asia because the teachers in Asia are willing to try out new methods to best serve their learners.

\section{Conclusion}

The flipped classroom seems to be well received in Asia, however the model is still in its infancy and implementing the concept in classrooms may be filled with barriers. While its benefits are numerous, the time needed for them to manifest may be drawn-out as different schools have different capacities at leaving their comfort zones.

The flipped classroom is a relatively new model to Asia and published trials are few. This report shows an encouraging response of preliminary trials in Asia to the model. An extensive search of flipped classroom case studies in Asia was conducted, using variables of the key words 'flipped classroom' so as to cast our net as wide as possible for identifying case studies. This was done with the aim of maximising the reliability of our results. Case studies conducted in a diverse number of disciplines were also collected hence our review shows that the flipped classroom is easily adaptable for various kinds of subject material. Based on our findings, we encourage schools of all levels and disciplines in Asia to take the plunge and test out flipped classroom teaching for them. Currently our results accurately reflect the viewpoint of users of the flipped classroom in Asia, however a review comprising of a larger scope of case studies, as they become available in the future, is essential to validate these early findings.

Flipping the classroom has captivated educators and learners worldwide. From this review, there is definitely potential for its growth in Asia. 
Globally, schools with a strong international culture may also find the results of this review of value for implementation of the flipped classroom in their schools. Ultimately, creating independent learners should be the goal of education, for 'education is the kindling of a flame, not the filling of a vessel' (Socrates).

\section{Reference}

1. Bergmann J, Sams A. Flip Your Classroom: Reach Every Student in Every Class Every Day. ISTE/ASCD;2012

2. Tucker B. The Flipped Classroom: Online instruction at home frees class time for learning. Education Next. 2012;1:82-83

3. Mehta NB, Hull AL, Young JB, Stoller JK. Just imagine: new paradigms for medical education. Acad Med. 2013 Oct;88(10):1418-23

4. Fitzpatrick M. Classroom Lectures Go Digital. The New York Times. [website]. Viewed 2014 August 26. Available from: http://www.nytimes.com/2012/06/25/us/25ih t-educside25.html?_r=1\&

5. Anderson N. More classroom flipping in colleges. The Washington Post [website]. Viewed 2014 August 26. Available from: http

http://www.washingtonpost.com/local/educa tion/more-classroom-flipping-incolleges/2013/03/11/0c425758-8a7f-11e298d9-3012c1cd8d1e_story.html

6. Nisbett R. The Geography of Thought: How Asians and Westerners Think Differently...and Why. Simon \& Schuster Inc. 2003.

7. Wang H. Teaching Asian Students Online: What Matters and Why? PAACE Journal of Lifelong Learning. 2006;15:69-84.

8. Li J. U.S and Chinese cultural beliefs about learning. Journal of Educational Psychology. 2003 Jun;95(2):258-267.

9. Horn M. The Transformational Potential of Flipped Classrooms: Different strokes for different folks. Education Next. 2013;13(3).

10. Strauss V. 'Flipping' classrooms: Does it make sense? The Washington Post. Viewed 2014 August 26. Available from: http://www.washingtonpost.com/blogs/answ er-sheet/post/flipping-classrooms-does-itmakesense/2012/06/06/gJQAk50vJV_blog.html

11. Liu, J. Asian students' classroom communication patterns in U.S universities:
An emic perspective. Greenwood Publishing Group; 1 Jan 2001.

12. Zhou, N. Historical context of educational reforms in present-day China. Interchange. 1988;19(3/4):8-18.

13. Hancocks P, Shoichet CE, Pearson M. South Korean shipwreck survivors: Passengers told 'don't move' as ship sank. CNN [website]. Viewed 2014 August 26. Available from http://edition.cnn.com/2014/04/16/world/asi a/south-korea-sinking-ship-students/

14. Nationsonline.org. Countries by Continents [website]. Viewed 2014 August 26. Available from: http://www.nationsonline.org/oneworld/asia. htm

15. Linga, $\mathrm{P}$, Wang $\mathrm{CH}$. Flipped class learning in a large class setting. CDTL Brief. 2014;17(1):4-9.

16. Corrias, A. Lightening up Mathematicsintensive classes: A case study using a flipped classroom approach. CDTL Brief. 2014;17(1):10-13.

17. Ong, P.S. A hybrid teaching method encompassing didactic lectures, short emodules and case scenarios to facilitate learning of pharmaceutical care principles. CDTL Brief. 2014;17(1):14-18.

18. Jamaludin R. Osman SZ. The Use of a Flipped Classroom to Enhance Engagement and Promote Active Learning. Journal of Education and Practice. 2014;5(2):124-131

19. Zhang Z. Construction of Online Course based on FCM concept. Atlantis Press. 2014 Jan.

20. Sureka A, Gupta M, Sarkar D, Chaudhary V. A Case-Study on Teaching UndergraduateLevel Software Engineering Course Using Inverted-Classroom, Large-Group, RealClient and Studio-Based Instruction Model. Cornell University Library. 2013 Sep 2.

21. Sharma N. The flipped classroom at the $\mathrm{Li}$ Ka Shing Faculty of Medicine [Powerpoint on Internet]. Viewed 2014 August 26. Available from: http://www.slideshare.net/citehku/622flipped-c-

citers?ref=http://citers2013.cite.hku.hk/en/pa per_622.htm

22. Choi EM. Applying Inverted Classroom to Software Engineering Education. International Journal of e-Education, eBusiness, e-Management and e-Learning. 2013 Apr; 3(2): 121-125.

23. Wan HT. Impact analysis of using OpenCourseWare to Flip the classroom examples in Taipei Medical University 
[webpage]. Viewed 2014 August 26.

Available from: http://conference.oeconsortium.org/2014/wp -content/uploads/2014/02/Paper_13-TaiwanMedical.pdf

24. Chen Y, Wang Y, Kinshuk, Chen NS. Is FLIP enough? Or should we use the FLIPPED model instead? Computers \& Education. 2014 Oct; 79:16-27.

25. Atabekova a. Public service interpreter and translator training in the flipped classroom: First steps to design learning materials. Iated Digital Library. 2013; 4149-4152.

26. Ishikawa Y, Yamada RA, Smith C, Tsubota $\mathrm{Y}$, Dantsuji M. Flipped learning in a university EFL course: Helping students improve their TOEIC scores. IATED Digital Library. 2014; 5860-5867

27. Heller M. Globalisation, the new economy, and the commodification of language and identity. Journal of Sociolinguistics, 2003 Dec 11;7:473-492.

28. Wheeler, David L. More students study abroad, but their stays are shorter. Chronicle of Higher Education. 2000 Nov;47(12):7477

29. Mullan F. The metrics of the physician brain drain. N Engl J Med. 2005;353:1810-1818.

30. Fok W. In an i-Class of its own. The Standard [website]. Viewed 2014 August 26. Available from: http://www.thestandard.com.hk/news_detail. asp?we_cat $=16 \&$ art_id $=125814 \&$ sid $=37478$ 680\&con_type $=3 \& d$ _str $=20120828 \& \mathrm{fc}=2$

31. DUKE-NUS Graduate Medical School Singapore [website]. Viewed 2014 August 26. Available from: https://www.dukenus.edu.sg

32. Singapore-MIT Alliance for Research and Technology [website]. Viewed 2014 August 26. Available from: http://smart.mit.edu 